\title{
Vitamin E supplementation may transiently increase tuberculosis risk in males who smoke heavily and have high dietary vitamin $\mathrm{C}$ intake
}

\author{
Harri Hemilä* and Jaakko Kaprio \\ Department of Public Health, University of Helsinki, Mannerheimintie 172, POB 41, Helsinki FIN-00014, Finland \\ (Received 31 August 2007 - Revised 7 January 2008 - Accepted 8 January 2008 - First published online 18 February 2008)
}

Vitamin $\mathrm{E}$ and $\beta$-carotene affect the immune function and might influence the predisposition of man to infections. To examine whether vitamin $\mathrm{E}$ or $\beta$-carotene supplementation affects tuberculosis risk, we analysed data of the Alpha-Tocopherol Beta-Carotene Cancer Prevention (ATBC) Study, a randomised controlled trial which examined the effects of vitamin E $(50 \mathrm{mg} / \mathrm{d})$ and $\beta$-carotene $(20 \mathrm{mg} / \mathrm{d})$ on lung cancer. The trial was conducted in the general community in Finland in 1985-93; the intervention lasted for 6.1 years (median). The ATBC Study cohort consists of 29023 males aged 50-69 years, smoking at baseline, with no tuberculosis diagnosis prior to randomisation. Vitamin E supplementation had no overall effect on the incidence of tuberculosis (risk ratio $(\mathrm{RR})=1 \cdot 18 ; 95 \%$ CI $0 \cdot 87,1 \cdot 59$ ) nor had $\beta$-carotene $(\mathrm{RR}=1 \cdot 07 ; 95 \% \mathrm{CI} 0 \cdot 80,1 \cdot 45$ ). Nevertheless, dietary vitamin C intake significantly modified the vitamin E effect. Among participants who obtained $90 \mathrm{mg} / \mathrm{d}$ or more of vitamin C in foods $(n$ 13 502), vitamin E supplementation increased tuberculosis risk by $72(95 \%$ CI 4,185$) \%$. This effect was restricted to participants who smoked heavily. Finally, in participants not supplemented with vitamin E, dietary vitamin $\mathrm{C}$ had a negative association with tuberculosis risk so that the adjusted risk was 60 (95\% CI 16, 81) \% lower in the highest intake quartile compared with the lowest. Our finding that vitamin E seemed to transiently increase the risk of tuberculosis in those who smoked heavily and had high dietary vitamin $\mathrm{C}$ intake should increase caution towards vitamin E supplementation for improving the immune system.

Adverse effects: Antioxidants: $\beta$-Carotene: Cohort studies: Randomised controlled trials

Vitamin E is extensively used as a nutrient supplement, for example, approximately $25 \%$ of the US population aged 60 or more used vitamin $\mathrm{E}$ supplements according to a recent survey $^{(1)}$. Such a high proportion of people taking vitamin E supplements makes the health effects of supplementation an important public health issue and raises the question of whether the effects are beneficial or not.

Many animal studies found that vitamin E increases resistance to various bacterial and viral infections ${ }^{(2)}$; however, vitamin $\mathrm{E}$ shortened the survival of mice with malaria ${ }^{(3,4)}$ and increased the multiplication of Leichmania parasites in hamsters ${ }^{(5)}$. Some human studies reported an apparent benefit of vitamin $\mathrm{E}$ on the immune system, such as an increase in the delayed type hypersensitivity responses ${ }^{(6)}$, whereas some other studies found no effects ${ }^{(2,7,8)}$. Moreover, three studies reported reduced bactericidal activity of phagocytes in subjects administered large doses of vitamin $\mathrm{E}^{(9-11)}$.

Only a few trials in man have examined the effect of vitamin E supplementation on clinical infectious disease outcomes, mainly respiratory tract infections ${ }^{(12-18)}$. On the whole, these trials found no consistent benefit from vitamin E. Paradoxically, one trial found an increase in the severity of acute respiratory infections with $200 \mathrm{mg} / \mathrm{d}$ vitamin $\mathrm{E}^{(13)}$. In our previous analyses of the Alpha-Tocopherol, Beta-Carotene Cancer Prevention (ATBC) Study cohort, we found no net effect on the incidence of the common cold or pneumonia with $50 \mathrm{mg} / \mathrm{d}$ vitamin $\mathrm{E}$; however, in both cases we found significant divergence in vitamin $\mathrm{E}$ effect so that certain participants obtained benefit while some others suffered harm from supplementation ${ }^{(16-18)}$.

Available studies suggest that also $\beta$-carotene influences the immune system $^{(7,8)}$. However, we found no effect of $20 \mathrm{mg} / \mathrm{d} \beta$-carotene on the incidence of the common cold and pneumonia in male smokers ${ }^{(15,17,18)}$. In addition, no effect on the incidence of respiratory and urinary tract infection was found in elderly patients treated with the combination of $6 \mathrm{mg} / \mathrm{d} \quad \beta$-carotene, $15 \mathrm{mg} / \mathrm{d}$ vitamin $\mathrm{E}$ and $120 \mathrm{mg} / \mathrm{d}$ vitamin $\mathrm{C}^{(19)}$.

The present paper presents the effects of 6-year supplementation with vitamin $\mathrm{E}$ or $\beta$-carotene on the incidence of hospital-treated tuberculosis in the ATBC Study cohort, a large, randomised, double-blind, placebo-controlled trial testing primary prevention of lung cancer. Previously we analysed the relationship between dietary vitamin $\mathrm{C}$ intake and the incidence of tuberculosis in the same cohort ${ }^{(20)}$.

Abbreviations: ATBC Study, Alpha-Tocopherol Beta-Carotene Cancer Prevention Study; ICD, International Statistical Classification of Diseases, Injuries, and Causes of Death; RR, relative risk.

* Corresponding author: Dr Harri Hemilä, fax +358 9191 27570, email harri.hemila@helsinki.fi 


\section{Methods}

\section{Participants}

The rationale, design and methods of the ATBC Study examining the effects of vitamin E (DL- $\alpha$-tocopheryl acetate, $50 \mathrm{mg} / \mathrm{d})$ and $\beta$-carotene $(20 \mathrm{mg} / \mathrm{d})$ on the incidence of lung cancer and other cancers have been described in detail elsewhere $^{(20-22)}$. To be eligible, male participants living in Finland, aged 50-69 years, had to smoke five or more cigarettes per day at entry, and those enrolled to the trial ( $n$ 29133) were randomised to one of four intervention groups and administered placebo ( $n$ 7287), vitamin $\mathrm{E}$ ( $n$ 7286), $\beta$-carotene $(n$ 7282) or vitamin $\mathrm{E}+\beta$-carotene ( $n$ 7278), using a $2 \times 2$ factorial design. The intervention continued for 5-8 years (median 6.1 years) until 30 April 1993. Compliance with supplementation was high: some $90 \%$ of the participants took more than $90 \%$ of their prescribed capsules during their active participation in the trial; there were no differences in capsule consumption among the intervention groups ${ }^{(22)}$. Compared with baseline levels, supplementation increased serum $\alpha$-tocopherol by $50 \%$, whereas serum $\beta$-carotene increased 15 -fold ${ }^{(22)}$. The trial was approved by the review boards of the participating institutions and all participants gave written informed consent. For the present analysis, we excluded participants who had had hospital-treated tuberculosis before randomisation ( $n$ 110), resulting in 29023 participants at study entry. ATBC Study is registered at ClinicalTrials.gov with identifier NCT00342992 (http:// clinicaltrials.gov/ct/show/NCT00342992).

\section{Baseline characteristics}

At baseline prior to randomisation the men completed questionnaires on their medical and smoking histories and general background characteristics. A detailed dietary history questionnaire was completed that provided data regarding daily food consumption ${ }^{(23)}$. The dietary intakes of vitamin $E, \beta$-carotene and vitamin $\mathrm{C}$ were calculated using the food composition database of the National Public Health Institute ${ }^{(24)}$. Vitamin C supplement usage was rare and the doses were small, therefore we ignored supplement usage in the analyses ${ }^{(20)}$. Dietary data were not available for 2009 participants and we excluded these men from the subgroup analyses focusing on diet. A chest X-ray was taken at baseline to exclude existing lung cancer and repeated every 28 months to enhance the ascertainment of lung cancer during the trial ${ }^{(22)}$.

\section{Outcome}

The events for the present study, the first hospital-treated tuberculosis between randomisation and 30 April 1993, were ascertained from the National Hospital Discharge Register using the unique personal identification number assigned to all Finnish citizens for linkage. The Register covers inpatient visits from all public and private hospitals in Finland. It uses the codes of the International Statistical Classification of Diseases, Injuries, and Causes of Death (ICD), the 8th edition (ICD-8) was used to the end of 1986, and the 9th edition (ICD-9) thereafter. Up to four diagnoses per each discharge are recorded, the primary diagnosis and three secondary diagnoses. The validity of the Finnish Hospital Discharge Register was examined from a random sample of 2211 discharges $^{(25)}$. The registered cause of hospitalisation was compared with the medical records and in $94.4 \%$ of the cases the same diagnosis was reached. In the category of infections the agreement was $88 \%$, based on thirty-three discharge records. Among infections, tuberculosis is particularly well defined and therefore the accuracy may be higher than the average.

For the present study, we defined tuberculosis by ICD- 8 and ICD-9 codes 010-018, and both primary and secondary diagnoses were accepted. There were 174 cases of new tuberculosis from 1985 to 30 April 1993. In 160 cases tuberculosis was in the respiratory tract (ICD-8 and ICD-9 codes 010-012). These included two cases of primary tuberculosis (010), 137 cases of pulmonary tuberculosis (011) and twenty-one cases of tuberculosis elsewhere in the respiratory tract (012). In fourteen cases tuberculosis was in other organs (013-018).

\section{Statistical analyses}

Follow-up time for each participant began from the day of randomisation, and continued until the date of first hospital discharge for tuberculosis, death or the end of the trial, 30 April 1993, whichever came first. The median follow-up time of the participants in the present analysis was 6.1 years, and there was a total of 168845 person-years of observation. Use of the Hospital Discharge Register allowed information on tuberculosis to be obtained in all study participants irrespective of whether they continued in or had dropped out from the trial.

We estimated the effects of vitamin $E$ and $\beta$-carotene supplementation on tuberculosis incidence through proportional hazards regression models. We calculated the risk ratio (RR) and the $95 \% \mathrm{CI}$ of the RR using the PROC PHREG program of the SAS package of programs (version 8.1; SAS Institute Inc., Cary, NC, USA). The $2 \times 2$ factorial design of the trial permitted assessment of the effects of vitamin $\mathrm{E}$ and $\beta$-carotene independently after confirming no statistical interaction between the agents at the level $P<0.05$. Thus, we compared one half of the trial participants administered vitamin $E$ with the other half not receiving vitamin $\mathrm{E}$ (the no-vitamin E group). Similarly, we compared one half of the trial participants administered $\beta$-carotene with the other half not receiving $\beta$-carotene (the no- $\beta$-carotene group). As to supplementation, we carried out the analyses following the intention-to-treat principle.

To test the statistical significance of interaction between supplementation and potential modifying factors, we first added the supplementation and the modifying factor to the regression model. The statistical significance of the interaction was thereafter calculated from the change in $-2 \times$ $\log$ (likelihood) when the interaction term for supplementation and the modifying factor were added to the model.

The major vitamin $\mathrm{C}$ sources in the diet of the study participants were fruit, vegetables and berries, on average $58 \%$ of calculated dietary vitamin $\mathrm{C}$ originated from these foods. The median vitamin $\mathrm{C}$ intake was $90 \mathrm{mg} / \mathrm{d}$. The total intake of fruit, vegetables and berries (FRUVEBE) was strongly correlated with the calculated vitamin $\mathrm{C}$ intake $(r$ 0.88). To analyse the possible role of dietary compounds other than vitamin $\mathrm{C}$ in these foods we calculated the residual of FRUVEBE intake (FRUVEBE-RES) using linear 
regression to model FRUVEBE as a function of dietary vitamin $\mathrm{C}$ as previously ${ }^{(20)}$ :

\section{FRUVEBE-RES (g/d)}

\section{$=\operatorname{FRUVEBE}(\mathrm{g} / \mathrm{d})-2.47 \times \operatorname{vitamin} \mathrm{C}(\mathrm{mg} / \mathrm{d})+35.4(\mathrm{~g} / \mathrm{d})$.}

As designed, FRUVEBE-RES had no correlation with dietary vitamin $\mathrm{C}$. We assume that any other putative compound that might interact with vitamin E supplementation has no perfect linear correlation with vitamin $\mathrm{C}$ and therefore variation in other compounds remains as variation in FRUVEBE-RES which was split at $0 \mathrm{~g} / \mathrm{d}$, close to median. High FRUVEBERES (over zero) indicates that the participant with a given vitamin $\mathrm{C}$ level consumes more than average amount of fruit, vegetables and berries, whereas low FRUVEBE-RES (below zero) indicates less than average intake of these food classes. Dietary vitamin E and $\beta$-carotene levels were split at rounded levels close to medians.

The interaction between vitamin $\mathrm{E}$ supplementation and continuous dietary vitamin $\mathrm{C}$ intake was calculated by first including the mean vitamin $\mathrm{E}$ supplement effect and dietary vitamin $\mathrm{C}$ intake (as square root to decrease the weight of distant points), adjusting for the number of cigarettes smoked, BMI and FRUVEBE-RES as continuous variables and for categorised age (50-59 or 60-69 years), marital status (married, never married, divorced, widowed) and residential neighbourhood (city/town or village/countryside) as previously ${ }^{(20)}$. Thereafter we added the interaction term between vitamin $\mathrm{E}$ and vitamin $\mathrm{C}$ and calculated the $P$ value from the change in $-2 \times \log$ (likelihood). After we found that dietary vitamin $\mathrm{C}$ has different trends in the vitamin $\mathrm{E}$ groups, we calculated the RR estimates for the vitamin $\mathrm{C}$ intake quartiles and tested the trend of tuberculosis risk over vitamin $\mathrm{C}$ intake adjusting for the same variables as earlier. We calculated the $P$ value for trend from the Wald test. We analysed the interaction between $\beta$-carotene supplementation and dietary vitamin $C$ intake in the same way.

The difference in tuberculosis incidence between FRUVEBE-RES below and above $0 \mathrm{~g} / \mathrm{d}$ was adjusted with the number of cigarettes smoked, BMI, age, marital status and residential neighbourhood.

Nelson-Aalen cumulative hazard functions were constructed using STATA sts graph program, release 9 (Stata Corp., College Station, TX, USA). Two-tailed $P$ values were used.

\section{Results}

The baseline characteristics of the ATBC Study participants have been described earlier ${ }^{(17,20)}$, and the subgroup analyses of Table 1 show the distribution of major characteristics. During 168845 person-years of follow-up of the study participants there were 174 new cases of hospital-diagnosed tuberculosis, representing a mean incidence rate of 103 cases per $10^{5}$ person-years of follow-up.

Supplementation with either vitamin E or $\beta$-carotene had no overall impact on the incidence of tuberculosis (Table 1).

In subgroup analyses we found that the effect of vitamin $\mathrm{E}$ supplementation was significantly modified by dietary vitamin $\mathrm{C}$ level so that vitamin $\mathrm{E}$ increased tuberculosis risk by $72 \%$ in those who obtained $90 \mathrm{mg} / \mathrm{d}$ or more of vitamin $\mathrm{C}$ in foods
(Table 1). The main food sources for vitamin $\mathrm{C}$ are fruit, vegetables and berries and we tested the possibility that other compounds in such foods might explain the interaction with vitamin E. Using linear regression to model fruit, vegetable and berry intake with dietary vitamin $\mathrm{C}$ intake as the explanatory variable, we calculated the residual intake of fruit, vegetables and berries. Vitamin E supplementation was not harmful for those who had high fruit, vegetable and berry residual intake (Table 1), indicating that the modification of vitamin $\mathrm{E}$ effect was not explained by other compounds in foods. The effect of vitamin E supplementation was not significantly modified by other tested variables (Table 1 ), or by the age of smoking initiation, BMI and residential neighbourhood (data not shown).

Because vitamin $\mathrm{E}$ supplementation and dichotomous dietary vitamin $\mathrm{C}$ intake showed a significant interaction, we analysed whether the association between continuous dietary vitamin $\mathrm{C}$ intake and tuberculosis risk differs between vitamin $\mathrm{E}$ and no-vitamin $\mathrm{E}$ participants, and we found significant divergence (interaction $P=0 \cdot 014$ ). In the no-vitamin $\mathrm{E}$ group, participants in the highest vitamin $\mathrm{C}$ quartile had $60 \%$ lower adjusted risk of tuberculosis compared with the lowest vitamin $\mathrm{C}$ intake quartile, whereas dietary vitamin $\mathrm{C}$ intake and tuberculosis risk had no association in the vitamin E-supplemented group (Table 2).

Heavy smoking was associated with a tendency of vitamin E to increase the risk of tuberculosis (Table 1) and previously smoking modified the effect of vitamin $\mathrm{E}$ on common cold and pneumonia incidence ${ }^{(16,17)}$. Therefore, we explored the combination of smoking and dietary vitamin $\mathrm{C}$. The apparent harm of vitamin $\mathrm{E}$ was restricted to those who smoked heavily at baseline and consumed vitamin $\mathrm{C}$ in amounts over the median (Table 3; Fig. 1). Nevertheless, the increased risk caused by vitamin E supplementation in this subgroup was restricted to a one-year period after the initiation of supplementation (Fig. 1). In the first year, there were twelve cases of tuberculosis in the vitamin $\mathrm{E}$ group but only two cases in the no-vitamin E group $(P=0.007$, Fisher's exact test). After the first year, the incidence of tuberculosis did not significantly differ between vitamin $\mathrm{E}$ and no-vitamin $\mathrm{E}$ groups, as shown by the similarity of the slopes in Fig. 1, yet there were more cases in the vitamin E group (nineteen $v$. twelve).

In our previous analysis ${ }^{(20)}$, we found that in heavy smokers with vitamin $\mathrm{C}$ intake over $90 \mathrm{mg} / \mathrm{d}$, high residual fruit, vegetable and berry intake was associated with a substantial reduction in tuberculosis risk. However, the vitamin $\mathrm{E}$ and no-vitamin E participants were combined in that study ${ }^{(20)}$. Because we found interaction between vitamins $\mathrm{E}$ and $\mathrm{C}$ in the current study, we analysed whether the effect of high residual fruit, vegetable and berry intake might differ between the vitamin $\mathrm{E}$ and no-vitamin $\mathrm{E}$ groups in heavy smokers with vitamin C intake over $90 \mathrm{mg} / \mathrm{d}$. Compared with the low residual fruit, vegetable and berry intake group, the high residual group had adjusted $\mathrm{RR}=0.35(95 \%$ CI $0 \cdot 15,0.83)$ in the vitamin $\mathrm{E}$ group, and adjusted $\mathrm{RR}=0.18(95 \% \mathrm{CI}$ $0.04,0.80)$ in the no-vitamin $\mathrm{E}$ group. Thus the lower risk of tuberculosis in the high fruit, vegetable and berry residual groups was not influenced by vitamin E supplementation.

$\beta$-Carotene supplementation did not interact with the variables we studied (Table 1), and it did not modify the 
Table 1. Relative risk of tuberculosis by vitamin E and $\beta$-carotene supplementation (the Alpha-Tocopherol Beta-Carotene Cancer Prevention Study, 1985-93) ${ }^{\star}$

\begin{tabular}{|c|c|c|c|c|c|c|c|c|c|c|c|c|c|c|c|}
\hline \multirow[b]{3}{*}{ Subgroup } & \multirow{3}{*}{$\begin{array}{c}\text { No. of } \\
\text { participants }\end{array}$} & \multicolumn{4}{|c|}{ Intervention } & \multirow[b]{3}{*}{$\mathrm{RR}$} & \multirow[b]{3}{*}{$95 \% \mathrm{Cl}$} & \multirow{3}{*}{$\begin{array}{c}\text { Test for } \\
\text { interaction } \\
P \text { value }\end{array}$} & \multicolumn{4}{|c|}{ Intervention } & \multirow[b]{3}{*}{$\mathrm{RR}$} & \multirow[b]{3}{*}{$95 \% \mathrm{Cl}$} & \multirow{3}{*}{$\begin{array}{c}\text { Test for } \\
\text { interaction } \\
P \text { value }\end{array}$} \\
\hline & & \multicolumn{2}{|c|}{ Vitamin $\mathrm{E}$} & \multicolumn{2}{|c|}{ No vitamin $\mathrm{E}$} & & & & \multicolumn{2}{|c|}{$\beta$-Carotene } & \multicolumn{2}{|c|}{ No $\beta$-carotene } & & & \\
\hline & & No. of cases & Rate & No. of cases & Rate & & & & No. of cases & Rate & No. of cases & Rate & & & \\
\hline All participants & 29023 & 94 & 111 & 80 & 95 & $1 \cdot 18$ & $0.87,1.59$ & & 90 & 107 & 84 & 99 & 1.07 & $0.80,1.45$ & \\
\hline \multicolumn{16}{|c|}{ Age at baseline (years) } \\
\hline $50-59$ & 19643 & 51 & 88 & 47 & 80 & $1 \cdot 10$ & $0.74,1.63$ & 0.6 & 47 & 81 & 51 & 87 & 0.93 & $0.63,1.39$ & 0.3 \\
\hline $60-69$ & 9380 & 43 & 162 & 33 & 126 & 1.28 & $0.81,2.02$ & & 43 & 162 & 33 & 126 & 1.28 & $0.81,2.02$ & \\
\hline \multicolumn{16}{|l|}{ Cigarettes per $d$} \\
\hline $5-19$ & 10513 & 26 & 86 & 26 & 85 & 1.01 & $0.58,1.74$ & 0.5 & 26 & 84 & 26 & 86 & 0.98 & $0.56,1.68$ & 0.6 \\
\hline$\geq 20$ & 18510 & 68 & 126 & 54 & 100 & 1.26 & $0.88,1.80$ & & 64 & 120 & 58 & 107 & $1 \cdot 12$ & $0.79,1.61$ & \\
\hline \multicolumn{16}{|c|}{ Dietary vitamin $C(\mathrm{mg} / \mathrm{d}) \dagger$} \\
\hline$<90$ & 13512 & 43 & 110 & 49 & 125 & 0.88 & $0.58,1.33$ & 0.042 & 49 & 127 & 43 & 109 & $1 \cdot 16$ & $0.77,1.75$ & 0.5 \\
\hline$\geq 90$ & 13502 & 41 & 103 & 24 & 60 & 1.72 & $1.04,2.85$ & & 31 & 78 & 34 & 86 & 0.91 & $0.55,1.48$ & \\
\hline \multicolumn{16}{|c|}{ Residual of fruit, vegetable and berries $(\mathrm{g} / \mathrm{d}) \dagger$} \\
\hline$<0$ & 14215 & 55 & 134 & 42 & 102 & 1.31 & $0.88,1.96$ & 0.3 & 52 & 126 & 45 & 110 & $1 \cdot 15$ & $0.77,1.71$ & 0.5 \\
\hline$\geq 0$ & 12799 & 29 & 77 & 31 & 82 & 0.95 & $0.57,1.57$ & & 28 & 75 & 32 & 84 & 0.90 & $0.54,1.49$ & \\
\hline \multicolumn{16}{|c|}{ Dietary vitamin $\mathrm{E}(\mathrm{mg} / \mathrm{d}) \dagger$} \\
\hline$<10$ & 11709 & 44 & 131 & 36 & 106 & 1.23 & $0.79,1.92$ & 0.7 & & & & & & & \\
\hline$\geq 10$ & 15305 & 40 & 89 & 37 & 82 & 1.08 & $0.69,1.69$ & & & & & & & & \\
\hline \multicolumn{16}{|c|}{ Dietary $\beta$-carotene $(\mathrm{mg} / \mathrm{d}) \dagger$} \\
\hline$<1.5$ & 11430 & & & & & & & & 41 & 124 & 43 & 131 & 0.95 & $0.62,1.46$ & 0.5 \\
\hline$\geq 1.5$ & 15584 & & & & & & & & 39 & 86 & 34 & 74 & $1 \cdot 15$ & $0.73,1.83$ & \\
\hline
\end{tabular}

RR, risk ratio.

Rate is given as the number of tuberculosis cases per 100000 person-years. RR was estimated using the proportional hazards regression model comparing participants who received vitamin $E$ and those who did not, and participants who received $\beta$-carotene and those who did not. No covariates were included in the model, because the comparison is between randomized groups. The sizes of all compared intervention groups are the same within $3 \%$ accuracy. † Data were missing for 2009 participants. 
Table 2. The risk of tuberculosis by dietary vitamin C intake in vitamin E-supplemented and non-supplemented participants (Alpha-Tocopherol Beta-Carotene Cancer Prevention Study)

\begin{tabular}{|c|c|c|c|c|c|}
\hline & \multicolumn{4}{|c|}{ Dietary vitamin $C$ intake divided by quartiles } & \multirow[b]{2}{*}{ Test for trend $P$ value } \\
\hline & Quartile 1 & Quartile 2 & Quartile 3 & Quartile 4 & \\
\hline Median (mg/d) & 52 & 78 & 103 & 148 & \\
\hline Range (mg/d) & $5-65$ & $66-89$ & $90-120$ & $121-534$ & \\
\hline \multicolumn{6}{|l|}{ No-vitamin E participants } \\
\hline Cases of tuberculosis & 30 & 19 & 14 & 10 & \\
\hline Adjusted RR* ${ }^{*}$ & 1.00 & 0.73 & 0.56 & 0.40 & 0.004 \\
\hline $95 \% \mathrm{Cl}$ & Reference & $0.41,1.30$ & $0.29,1.06$ & $0.19,0.84$ & \\
\hline \multicolumn{6}{|l|}{ Vitamin E participants } \\
\hline Cases of tuberculosis & 22 & 21 & 25 & 16 & \\
\hline Adjusted RR* ${ }^{\star}$ & 1.00 & 1.03 & 1.31 & 0.90 & 0.6 \\
\hline $95 \% \mathrm{Cl}$ & Reference & $0.57,1.89$ & $0.73,2.35$ & $0.46,1.74$ & \\
\hline
\end{tabular}

$\mathrm{RR}$, risk ratio.

*Proportional hazards regression model comparing vitamin $\mathrm{C}$ groups to the lowest vitamin $\mathrm{C}$ group. Adjusted for the number of cigarettes smoked, BMI, age, marital status, residential neighbourhood and the residual of fruit, berry and vegetable intake. The number of participants in each of the eight groups varies between 3350 and 3404 .

association between dietary vitamin $\mathrm{C}$ and tuberculosis risk $(P=0 \cdot 2)$.

\section{Discussion}

Vitamin E did not reduce tuberculosis risk in the ATBC Study cohort. This finding along with our previous findings ${ }^{(15-17)}$ refute the proposal that vitamin E supplementation would have wide-ranging benefits on the immune system and protect against diverse infections in the aged people ${ }^{(7)}$.

Vitamin E increased the risk of tuberculosis in participants with high dietary vitamin $\mathrm{C}$ intake levels, but the harm was restricted to those who were smoking heavily at baseline (Table 3). In two earlier analyses of the ATBC Study cohort, focusing on the common cold and pneumonia, we found significant divergence in the effects of vitamin E so that certain participants got benefit from supplementation, whereas some others were harmed. The harms were restricted to those who smoked heavily at baseline or had initiated

Table 3. The effect of vitamin E supplementation on tuberculosis risk: modification by smoking and dietary vitamin C intake (Alpha-Tocopherol Beta-Carotene Cancer Prevention Study)

\begin{tabular}{|c|c|c|}
\hline \multirow[b]{2}{*}{ Cigarettes per $d$ at baseline } & \multicolumn{2}{|c|}{ Dietary vitamin C (mg/d) } \\
\hline & $<90$ & $\geq 90$ \\
\hline \multicolumn{3}{|l|}{$5-19$} \\
\hline $\mathrm{RR}^{\star}$ & 1.04 & 0.99 \\
\hline $95 \% \mathrm{Cl}$ & $0 \cdot 50,2 \cdot 19$ & $0.41,2.37$ \\
\hline Cases of tuberculosis $†$ & $14 / 14$ & $10 / 10$ \\
\hline No. of participants & 4439 & 5330 \\
\hline \multicolumn{3}{|l|}{$\geq 20$} \\
\hline $\mathrm{RR}^{\star}$ & 0.82 & $2 \cdot 25$ \\
\hline $95 \% \mathrm{Cl}$ & $0.50,1.33$ & $1 \cdot 19,4 \cdot 23$ \\
\hline Cases of tuberculosis† & 29/35 & $31 / 14$ \\
\hline No. of participants & 9073 & 8172 \\
\hline
\end{tabular}

$\mathrm{RR}$, risk ratio.

* Proportional hazards regression model comparing participants who received vita$\min \mathrm{E}$ and those who did not. No covariates were included in the model, because the comparison is between randomised groups. The sizes of the compared vita$\min E$ and no-vitamin $E$ groups are the same with $4 \%$ accuracy.

$\dagger A / B$ refers to $A$ cases in vitamin $E$ participants and $B$ cases in no-vitamin $E$ participants. smoking at an early age ${ }^{(16,17)}$. In this respect, the increase in tuberculosis risk with vitamin $\mathrm{E}$ in heavy smokers is consistent with our earlier findings.

Vitamin E supplementation caused a transient increase in the incidence of tuberculosis in heavy smokers with high dietary vitamin $\mathrm{C}$ intake. Evidently, this temporary increase was not caused by new infections in the ATBC participants, but by the reactivation of old infectious foci. The ATBC Study participants were mostly born in the 1920s and 1930s, and in the 1930s about $80 \%$ of the Finnish population were infected by Mycobacterium tuberculosis ${ }^{(26)}$. Mortality caused by tuberculosis was high and Finland was sometimes referred to as 'the black area on the European tuberculosis map, (26). Currently latent tuberculosis infections in the

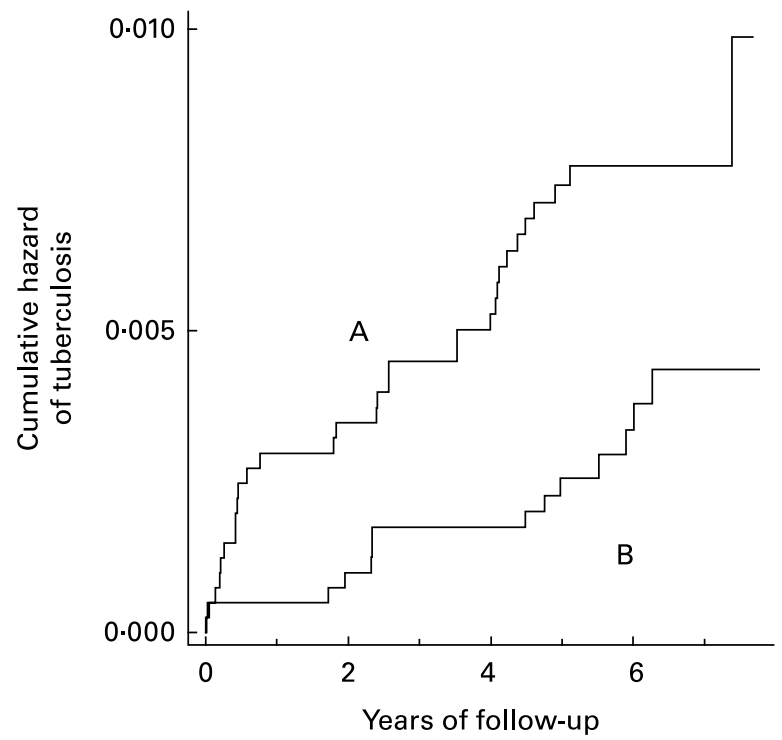

Fig. 1. Vitamin E supplementation and tuberculosis risk in Alpha-Tocopherol Beta-Carotene Cancer Prevention Study participants smoking twenty or more cigarettes per $d$ with dietary vitamin $C$ intake $\geq 90 \mathrm{mg} / \mathrm{d}(n$ 8172). Nelson-Aalen cumulative hazard functions for vitamin $E(A)$ and no-vitamin $E$ (B) groups are shown. Each step indicates one case of tuberculosis. The logrank test gives $P=0.010$ for the difference between the two curves and the Wilcoxon test, which puts greater weight on the early observations, gives $P=0.005$. 
young generations are rare in developed countries, but globally some third of all people are infected by M. tuberculosis ${ }^{(27)}$. Thus, the harm we observed probably is not of major concern in high-income countries, but might be important in some of the developing countries, in which smoking and latent tuberculosis are prevalent. Although vitamin $\mathrm{E}$ doubled the risk of tuberculosis in the heavy smokers with high dietary vitamin $\mathrm{C}$ intake, only a few participants caught tuberculosis. In this respect the observed increase in tuberculosis risk should not be exaggerated.

A recent review concluded that vitamin E supplementation is safe for most adults in amounts up to $1000 \mathrm{mg} / \mathrm{d}^{(28)}$. However, a recent meta-analysis found that, starting from $150 \mathrm{mg} / \mathrm{d}$, vitamin E supplementation seemed to increase mortality $^{(29)}$ and the large HOPE-TOO trial found increases in hospitalisation due to heart failure with $400 \mathrm{Iu} / \mathrm{d}$ vitamin $\mathrm{E}^{(30)}$. Furthermore, a Dutch trial with older people reported more severe symptoms of respiratory infections in those administered $200 \mathrm{mg} / \mathrm{d}$ vitamin $\mathrm{E}^{(13)}$. Our analyses of the ATBC Study cohort indicate that in restricted groups of people vitamin E supplementation may be harmful at a lower dose, $50 \mathrm{mg} / \mathrm{d}$ (Table 3) ${ }^{(16,17)}$. Still, the findings suggest that there is biological heterogeneity between population groups, so that people's characteristics determine whether vitamin E supplements cause net benefit or harm and in this respect the dosage of vitamin E may be an issue secondary to the personal characteristics.

In a previous analysis of tuberculosis cases in the ATBC Study cohort, we focused on the relation between dietary vitamin $C$ intake and the risk of tuberculosis ${ }^{(20)}$. Vitamin E supplementation had no overall impact on tuberculosis risk, which then justified us to ignore vitamin $\mathrm{E}$ when focusing on dietary vitamin $\mathrm{C}$. In the current study, we found significant interaction between vitamins $\mathrm{E}$ and $\mathrm{C}$ : high dietary vitamin $\mathrm{C}$ intake was associated with a lower tuberculosis risk in the no-vitamin $\mathrm{E}$ participants, but no similar association was seen in the vitamin E participants (Table 2). Furthermore, this interaction between vitamins $\mathrm{E}$ and $\mathrm{C}$ was not explained by other components of fruit, vegetables and berries. The negative association between dietary vitamin $\mathrm{C}$ and tuberculosis risk in the no-vitamin $\mathrm{E}$ participants is consistent with several guinea pig studies reporting benefit of vitamin $\mathrm{C}$ against tuberculosis ${ }^{(2)}$

The interaction between vitamins $\mathrm{E}$ and $\mathrm{C}$ is interesting as the water-soluble antioxidant vitamin $\mathrm{C}$ regenerates the lipidsoluble antioxidant vitamin $\mathrm{E}$ in vitro and in vivo ${ }^{(2,31,32)}$, and both of them influence the immune system ${ }^{(2,7,8)}$. Smoking causes oxidation of vitamin $\mathrm{C}$ as indicated by the increased plasma levels of dehydroascorbate, the oxidised form of vitamin $\mathrm{C}^{(33)}$. Furthermore, smoking increases plasma $\alpha$-tocopherol disappearance rate, which is normalised by vitamin $\mathrm{C}$ supplementation ${ }^{(34)}$, implying that smoking modifies the interaction between these two antioxidants. To our knowledge, the present study is the first to show interaction between vitamins $\mathrm{C}$ and $\mathrm{E}$ with a clinically relevant outcome. However, contrary to the anticipations based on biochemical studies, we found evidence to suggest that the combination of high dietary vitamin $\mathrm{C}$ intake and vitamin $\mathrm{E}$ supplementation is harmful in heavy smokers (Table 3; Fig. 1).

It has been proposed that $\beta$-carotene improves the immune system $^{(7,8)}$, but it did not affect tuberculosis risk in the ATBC
Study population or in any subgroup that we studied. Earlier studies found no indications that $\beta$-carotene would protect against clinical infections ${ }^{(15,17-19)}$. Furthermore, two largescale trials found that $\beta$-carotene supplementation increased total mortality ${ }^{(21,35)}$.

In conclusion, it has been proposed that vitamin $\mathrm{E}$ and $\beta$-carotene supplementation might lead to wide-ranging benefits on the immune system. The present study found that neither of these two compounds increased resistance against tuberculosis in middle-aged male smokers. In contrast, vitamin E appeared to transiently increase the incidence of tuberculosis in participants who smoked heavily and had dietary vitamin $\mathrm{C}$ intake of $90 \mathrm{mg} / \mathrm{d}$ or over. Although vitamin $\mathrm{E}$ may be beneficial in restricted population groups $^{(16-18)}$, those groups are poorly defined so far. The consumption of vitamin E supplements by the general population should be discouraged because there is evidence of harm for some people.

\section{Acknowledgements}

We thank the ATBC Study for the access to the data. H. H. had full access to all of the data in the study and takes responsibility for the integrity of the data and the accuracy of the data analysis. Our study was not funded by sources outside of our university. We have no conflicts of interest. H. H. planned the study and wrote the draft of the manuscript and J. K. participated in planning the analyses and in the critical revision of the manuscript.

\section{References}

1. Radimer K, Bindewald B, Hughes J, Ervin B, Swanson C \& Picciano MF (2004) Dietary supplement use by US adults: data from the National Health and Nutrition Examination Survey, 1999-2000. Am J Epidemiol 160, 339-349.

2. Hemilä H (2006) Do vitamins $C$ and $E$ affect respiratory infections? Dissertation, University of Helsinki. http://ethesis. helsinki.fi/julkaisut/laa/kansa/vk/hemila/

3. Eaton JW, Eckman JR, Berger E \& Jacob HS (1976) Suppression of malaria infection by oxidant-sensitive host erythrocytes. Nature 264, 758-760.

4. Taylor DW, Levander OA, Krishna VR, Evans CB, Morris VC \& Barta JR (1997) Vitamin E-deficient diets enriched with fish oil suppress lethal Plasmodium yoelii infections in athymic and scid/bg mice. Infect Immun 65, 197-202.

5. Garg R, Singh N \& Dube A (2004) Intake of nutrient supplements affects multiplication of Leishmania donovani in hamsters. Parasitology 129, 685-691.

6. Meydani SN, Barklund MP, Liu S, Meydani M, Miller RA, Cannon JG, Morrow FD, Rocklin R \& Blumberg JB (1990) Vitamin E supplementation enhances cell-mediated immunity in healthy elderly subjects. Am J Clin Nutr 52, 557-563.

7. Meydani SN, Wu D, Santos MS \& Hayek MG (1995) Antioxidants and immune response in aged persons: overview of present evidence. Am J Clin Nutr 62, 1462S-1476S.

8. Webb AL \& Villamor E (2007) Update: effects of antioxidant and non-antioxidant vitamin supplementation on immune function. Nutr Rev 65, 181-217.

9. Baehner RL, Boxer LA, Allen JM \& Davis J (1977) Autoxidation as a basis for altered function by polymorphonuclear leukocytes. Blood 50, 327-335. 
10. Prasad JS (1980) Effect of vitamin E supplementation on leukocyte function. Am J Clin Nutr 33, 606-608.

11. Kaul N, Devaraj S \& Jialal I (2000) Effect of alpha tocopherol supplementation on phagocytosis and killing of Staphylococcus aureus in healthy volunteers (abstract). FASEB $J$ 14(4), A520.

12. Harman D \& Miller RW (1986) Effect of vitamin E on the immune response to influenza virus vaccine and the incidence of infectious disease in man. Age 9, 21-23.

13. Graat JM, Schouten EG \& Kok FJ (2002) Effects of daily vitamin $\mathrm{E}$ and multivitamin-mineral supplementation on acute respiratory infections in elderly persons. JAMA 288, 715-721.

14. Meydani SN, Leka LS, Fine BC, Dallal GE, Keusch GT, Singh MF \& Hamer DH (2004) Vitamin E and respiratory tract infections in elderly nursing home residents. JAMA 292, 828-836. Comments in: JAMA (2004) 292, 2834.

15. Hemilä H, Kaprio J, Albanes D, Heinonen OP \& Virtamo J (2002) Vitamin C, vitamin E, and beta-carotene in relation to common cold incidence in male smokers. Epidemiology 13, $32-37$.

16. Hemilä H, Virtamo J, Albanes D \& Kaprio J (2006) The effect of vitamin $\mathrm{E}$ on common cold incidence is modified by age, smoking and residential neighborhood. J Am Coll Nutr 25, $332-339$.

17. Hemilä H, Virtamo J, Albanes D \& Kaprio J (2004) Vitamin E and beta-carotene supplementation and hospital-treated pneumonia incidence in male smokers. Chest 125, 557-565.

18. Hemilä H, Kaprio J, Albanes D \& Virtamo J (2006) Physical activity and the risk of pneumonia in male smokers administered vitamin E and $\beta$-carotene. Int J Sports Med 27, 336-341.

19. Girodon F, Galan P, Monget AL, et al. (1999) Impact of trace elements and vitamin supplementation on immunity and infections in institutionalized elderly patients. Arch Intern Med 159, 748-754.

20. Hemilä H, Kaprio J, Pietinen P, Albanes D \& Heinonen OP (1999) Vitamin C and other compounds in vitamin C rich food in relation to risk of tuberculosis in male smokers. Am $J$ Epidemiol 150, 632-641.

21. The Alpha-Tocopherol, Beta-Carotene Cancer Prevention Study Group (1994) The effect of vitamin E and beta-carotene on the incidence of lung cancer and other cancers in male smokers. $N$ Engl J Med 330, 1029-1035.

22. The ATBC Cancer Prevention Study Group (1994) The alphatocopherol, beta-carotene lung cancer prevention study: design, methods, participant characteristics, and compliance. Ann Epidemiol 4, 1-10.
23. Pietinen P, Hartman AM, Haapa E, Rasanen L, Haapakoski J, Palmgren J, Albanes D, Virtamo J \& Huttunen J (1988) Reproducibility and validity of dietary assessment instruments. I. A self-administered food use questionnaire with a portion size picture booklet. Am J Epidemiol 128, 655-666.

24. Ovaskainen ML, Valsta L \& Lauronen J (1996) The compilation of food analysis values as a database for dietary studies: the Finnish experience. Food Chem 57, 133-136.

25. Keskimäki I \& Aro S (1991) Accuracy of data on diagnosis, procedures and accidents in the Finnish hospital discharge register. Int J Health Sci 2, 15-21.

26. Härö AS (1998) Tuberculosis in Finland: Dark Past - Promising Future. Tuberculosis and Respiratory Diseases Yearbook, vol. 24. Helsinki: The Finnish Lung Health Association.

27. Dye C, Scheele S, Dolin P, Pathania V \& Raviglione MC (1999) Global burden of tuberculosis: estimated incidence, prevalence, and mortality by country. WHO Global Surveillance and Monitoring Project. JAMA 282, 677-686.

28. Hathcock JN, Azzi A, Blumberg J, et al. (2005) Vitamins E and $\mathrm{C}$ are safe across a broad range of intakes. Am J Clin Nutr 81, 736-745. Comments in: Am J Clin Nutr (2005) 82, 1141-1143.

29. Miller ER, Pastor-Barriuso R, Dalal D, Riemersma RA, Appel LJ \& Guallar E (2005) Meta-analysis: high-dosage vitamin E supplementation may increase all-cause mortality. Ann Intern Med 142, 37-46. Comments in: Ann Intern Med (2005) 143, $150-158$.

30. The HOPE and HOPE-TOO Trial Investigators (2005) Effects of long-term vitamin $\mathrm{E}$ supplementation on cardiovascular events and cancer: a randomized controlled trial. JAMA 293, $1338-1347$.

31. Sharma MK \& Buettner GR (1993) Interaction of vitamin C and vitamin $\mathrm{E}$ during free radical stress in plasma: an ESR study. Free Radic Biol Med 14, 649-653.

32. Hamilton IMJ, Gilmore WS, Benzie IF, Mulholland CW \& Strain JJ (2000) Interactions between vitamins $C$ and $E$ in human subjects. Br J Nutr 84, 261-267.

33. Lykkesfeldt J, Loft S, Nielsen JB \& Poulsen HE (1997) Ascorbic acid and dehydroascorbic acid as biomarkers of oxidative stress caused by smoking. Am J Clin Nutr 65, 959-963.

34. Bruno RS, Leonard SW, Atkinson J, Montine TJ, Ramakrishnan R, Bray TM \& Traber MG (2006) Faster plasma vitamin E disappearance in smokers is normalized by vitamin C supplementation. Free Radic Biol Med 40, 689-697. Comments in: Free Radic Biol Med (2007) 42, 578-580.

35. Omenn GS (1998) Chemoprevention of lung cancer: the rise and demise of beta-carotene. Annu Rev Public Health 19, 73-99. 